\title{
The design and reconstruction of the geographical landscape is realized in the rural fragile space
}

\author{
Ding Fanzhuo ${ }^{1}$; Zhang Jixiao ${ }^{2}$ \\ ${ }^{1}$ School of Art and Design, Beijing Forestry University, Beijing 100083, China \\ ${ }^{2}$ School of Art and Design, Beijing Forestry University, Beijing 100083, China \\ Practice in Jingjiang Yinglin town quarry landscape renewal
}

\begin{abstract}
In the face of the two-way threat of the deteriorating natural environment and accelerating urbanization progress, the countryside has obvious landscape fragile characteristics, such as water and soil erosion, land desertification and industrial ruins left, some of spaces are even harder to remedy. It is of great significance and value for the planning and construction of rural areas to study the fragile space of rural landscape, identify the cause of its fragile and carry out landscape design and reconstruction.
\end{abstract}

\section{Introduction}

In the process of rapid urbanization, the countryside has left many abandoned industrial production sites. After losing their functions, these sites have not been well transformed. Meanwhile, the ecological status is extremely difficult, thus forming many fragile space in the countryside. How to solve the ecological restoration and governance scientifically has become a major problem in the rural sustainable development. The abandoned quarry is also one of the fragile sites that have an impact on the rural nature ecological environment. The abandoned quarry is an extremely degraded ecological system formed under the serious disturbance of human production activities. What kind of design method can make it be "activities" by science has become a hot issue.

\section{Rural fragile space concept feature}

\subsection{Fragile space concept}

In the 1990s, experts and scholars such as Hessburg, Gruber, etc proposed the study of landscape fragility, which includes more broadly significance and emphasize the important role of human environment. At present, scholars generally define landscape fragility as "the probability of damage caused by sensitivity and lack of adaptive capacity of landscape system in the interaction between natural environment and human activities" [1][2]. In a word, the study of landscape has become frontier scientific issues describing the relationship between human and land dependence and explore the nature landscape system operation mechanism under the interference of human social activities. as a necessary part of the landscape fragility research, fragile space research is an in-depth exploration of landscape fragility research.

\subsection{The causes of rural fragile space and its research significance}

The basement of ecological environment in China is relatively fragile, the area of ecological fragile area is large, and the factors of fragility are complex [3]. Faced with the "double-pronged attack" of the rapid deterioration of natural environment and rapid development of urbanization, one the one hand, the destruction of rural ecological system mainly refers to the nature tendency of soil desertification, soil erosion, grassland degradation and biodiversity reduction that threaten the environment due to unreasonable planning. On the other hand, man-made environment pollution in rural areas refers to the agricultural pollution, water pollution and solid pollution in rural areas, which also can be summarized as the impact of chemical residues brought by man-made farming life on nature environment. The fragility of the rural landscape is becoming more and more serious, whether the rural fragility space can be reused, the research of fragility is not only an advanced theoretical subject, but also has practical significance and function for the construction of beautiful countryside in China ${ }^{[4]}$.

\section{The connotation and expression of geo-cultural landscape}

On the space of non-homogeneous geographical environment, after thousand of years of inheritance, change, continuity, the geographical culture formed has diversified culture types and cultural symbols, and is the crystallization and essence of cultural ecology in the overall regional humanistic ecological system [5]. Therefore geographical culture is unique, local and pluralistic.

The range of geo-culture is very extensive, including not only the nature ecological environment of the region, 
but also the behavioral habits, life styles, traditional culture and spiritual yearning formed in the progress of social development. Unfortunately, after the vicissitudes of history, many important events, people and places with regional characteristics are often only preserved in books or people's oral narration, without specific expression. Therefore, it is one of the most important means to select on part to be reproduced in landscape construction in the excavation of geographical culture.

The rural geo-cultural landscape on the basis of the rural physical environment, and adopt the historical and culture scenes with local characteristics such as the culture formed in the process of agricultural production and folk customs, such as reproducing the farming landscape, planting folk cultural element, constructing the traditional architectural symbols with region characteristics, and the cultural symbols with celebrities and historic sites.

\section{The idea of reconstruction of rural fragile space landscape with the characteristics of geo-cultural landscape}

Ecological restoration and landscape reconstruction of rural fragile space must based on the premise of sustainable development, the premise of resource protection, the harmony between man and nature and the diversity of ecological environment. Meanwhile, the process should integrate artistic means, perfect and introduce the core content of geographical culture, excavate the original cultural value inside the village, and promote the development and change of contemporary rural villages with all one's strength ${ }^{[6]}$

In the paper, landscape design will be used to activate the fragile space of the countryside by combining the geographical culture. The design focuses on the interaction and mutual influence between geographical culture and landscape design. First, through the in-depth exploration and study of the geographical culture, we can get more meaningful inspiration for landscape design. Only on the basis of in-depth understanding of the origin of regional unique geographical culture and analyzing its development process and following the interaction between human culture and nature can interpret the regional culture in landscape design. At the same time, landscape design also provides the material carrier for the development and dissemination of geographical culture, so that the geographical culture is constantly remembered and continued through design. The landscape design based on the geographical culture requires to make full use of the existing regional characteristic elements, from the landscape characteristics of nature environment to the features of cultural heritage, to build a landscape integrated into the overall human behavior space.

\section{Geo-landscape reconstruction and design expression of quarry, Yinglin Town, Jinjiang}

\subsection{Background and current situation}

Since the history of Jinjiang city, granite resources have been rich and widely used by the people. Since the Jin Dynasty, there have been cultural marks of stone caving in all dynasty, and many dwelling and stone bridges are based on granite. With the increasing popularity of Jinjiang granite, the scale of quarry has been expanding, and the number of quarry has increased sharply. Therefore, the natural environment has been damaged to different degrees. In recent years, by referring to the ecological restoration technology used by other quarries at home and abroad, the city has dealt with on the local ecological problems of the quarry, caused by a lack of analysis of the regional natural geographical elements, controls the lax to repair the beautiful degree, that appeared after the restoration of no local characteristics, utilization rate is low, the overall effect is not good.

The plant landscape is too monotonous and meagre. Due to industrial operation, all the original vegetation was cut down, and now it is mainly composed of natural weeds and wild trees, the varieties are monotonous and randomly distributed, without ecological aesthetic feeling. As there is a large area of granite blocks under the whole quarry, the covering soil is relatively thin, and the soil is easy to be drained under the rain, causing soil erosion, resulting in poor soil. In addition, the sea breeze will affect the growth and development of vegetation.

The terrain is too rough. The original topography was designed with the sunken space as the core, with a low center, high and low surrounding terrain, and the view was often obscured by trees. There is no transition or connection between the barren land and the modern buildings of the surrounding city and the lifeless mountains in the distance, which cannot make a comprehensive and attractive visiting environment.

The abandonment of the quarry. The sunken space made up of quarries give a deep and mysterious feeling. The surrounding rock walls are also made of exposed stones. However, due to the great difference in height between the ground and the sunken space, and the lack of functional gathering places, it is difficult for tourists to approach the bottom, so the sunken space is always abandoned. At the same time, because of the subtropical monsoon climate, Quanzhou area more rain, so there is a lot of water at the bottom of the quarry.

Lack of public facilities: the original plot was abandoned, so there are no public facilities, in order to better create the effect of "gathering popularity" after opening the visit function of the site, some public facilities for people to have a rest, enjoy the cool and play must be set up. At the same time, in order to better guide the flow of people for a smooth tour experience, it should be added to guide the identification system.

\subsection{Geo-landscape reconstruction strategy}

The key significance of quarry design lies in the reconstruction of harmonious post-industrial landscape structure. To reconstruct the landscape integration of artificial ruins and natural vegetation, highlight the historical traces of abandoned quarries, integrate the local geo-cultural elements of Jinjiang into the public facilities 
and landscape design, build a quarry park with historical charm, local characteristics and transformation significance, fully activate the rural fragile space and reshape the rural landscape.

\subsection{1 vegetation restoration}

under the premise of following the ecological principle, the fast-growing trees, vines

herbs suitable for the growth of local granite hilly areas were selected. Eucalyptus Dunne and Masson's pine mixed forests are selected as the main arbor plants. Eucalyptus Dunne belongs to evergreen trees, which is an ideal tree species in the central Tropical region. It not only grows fast and has good quality, but also has good texture, cold, high temperature resistance. Its trunk straightness is better than that of Eucalyptus grandis, and it is used for paper and sawn timber. Wood density and cold resistance are greater than Eucalyptus grandis. Pinus massoniana has litter requirement for soil quality, and is resistant to thin and dry soil. It is suitable for slightly alkaline seashore sand and acidic yellow soil and lateritic soil developed from tuff. Strong adaptability to climate, high temperature resistance, cold resistance. Subzero temperatures can also survive ${ }^{[7]}$. On the high and steep around the quarry pit, as well as on the corner of the mountain, you can plant some vines such as ivy flower, which can not only beautify the rock mass, but also play a role in increasing oxygen, reducing temperature, reducing dust, reducing noise, and consolidating the soil. Mine rock belongs to the tilt state, planting local herbs such as buffalo grass, the grass stem soft, also has certain elasticity and tramping resistance. Buffalo grass is often used as a ground cover material, not only can keep the soil and water loss, and can add a little green landscape to consolidate soil firmness, let the earth's surface at the same time adds life and green. Bison grass is easy to take care of, and with a little care, you can keep your lawn in good condition.

\subsubsection{Functional activation of quarry pits}

Although the special form of the quarry wasteland presents a challenge to the designer, it is precisely because of its special features that the design can make use of the natural landscape to create a different and special landscape. Because of the special nature of the terrain, designer need to carefully examine the structure of the terrain, and at the same time, they can better find the geographical factors that can be utilized. It uses the advantage of the large drop of the quarry to construct the bottom along the mountain plank road, which is infinitely close to the artificial lake, so as to wake up the tour function of the bottom space. For example, the straight rock face of the quarry can be used as a ladder connecting the top and bottom of the quarry, which can provide an interesting shock during the climbing process, conversely, a unique pleasure of sightseeing. The winding hiking trial can be used as a place for people to climb mountains and exercise, as well as to feel the posture of the quarry from multiple angles.

The landscape design of water area can start from many aspects, and make use of the original water, purification, sewage treatment and so on, so as to form a small lake formed by several different sizes of water pits in series. Through the induction and treatment of natural terrain, the combination of natural revetment and artificial mooring bank can be used to adjust the scale sense of waterscape space. The second is to restore the natural texture of the rock revetment and combine with vegetation to create a natural waterscape. In the end, trestle road, trestle bridge, hydrophile platform and other facilities should be set up on the shallow part of the water surface to form a water-loving footpath system around the lake as far as possible ${ }^{[8]}$. It is difficult for abandoned industrial sites to produce good effects with exposed rocks in the process of greening and rehabilitation, or it needs a long period to achieve a certain harmonious effect. Therefore, the characteristics of rocks should be considered as far as possible, and the landscape foundation should be established. Then, through the embellishment of characteristic structures in the green river, different landscape effects in the near future, medium-term and long-term can be achieved build a very good waterfront landscape leisure place.

\subsection{The construction of local geographical and cultural landscape}

Yinglin Town, Jinjiang City, Minnan region of Fujian Province, is the hometown of Ke Xianxi, the first generation successor of The intangible cultural heritage of Gaojia Opera. Jinjiang is also a city with profound cultural deposits of GaoJia Opera, so Jinjiang is also known as one of the birthplace of GaoJia Opera. Such a city with profound cultural deposits, its cultural heritage once disappeared. In addition to the important culture of opera, the ancient house of red brick in the base is also one of its features. The red brick culture is an important representative of the architectural culture in southern Fujian, with profound historical origins and cultural deposits. The culture of traveling to the sea is also a characteristic social behavior activity for the residents in the southern Fujian province. People who live by the sea all year round are good at making use of the law of the tide to catch or collect the freshest "sea goods" from the beaches and reefs of the coast, which is also known as the process of chasing the sea.

This design combines the characteristics of the time to develop and transform intangible cultural heritage, focusing on the integration of minnan characteristic cultural with public facilities, green landscape and organic integration, and transforming the cultural resources hidden in memory into the contemporary material carrier. For example, the intangible cultural heritage opera Gaojia opera is derived into the drama theme children's paradise, red brick is consciously used to form a unified color texture, etc. intangible traditional skills, life activities and tangible structures, signs, public facilities and corresponding resources in the transformation of quarry pit are excavated, sorted and transformed, so that intangible cultural heritage can be more imperceptibly integrated into people's daily life, It can not only be 
inherited, but also improve the cultural and artistic taste of the quarry pit reconstruction.

By summing up the geographical cultural elements and injecting them into the design, Gaojia opera culture, red brick culture and sea driving cultural are well integrated with the characteristics of the base, which not only improves the playability of the quarry, but also ensures the "sense of belonging" of villagers when they play; so as to create a landscape visual environment with rich cultural characteristics and high restoration degree, so that the local cultural elements and culture in this quarry can be reflected and activation.

\section{Conclusion}

Through the exploration of the basic characteristics of the rural fragile space, and through field research, the basic status of the quarry pit was understood, and the landscape design of the abandoned quarry pit in Yinlin Town of Jinjiang was reconstructed by integrating the geographical culture of southern Fujian. This paper attempts to activate the abandoned and fragile space in rural areas by means of design, so as to add a place with local characteristics and ornamental value as well as recreational activities. In order to "transform waste into treasure", through the transformation to obtain the greatest social and ecological benefits.

\section{Reference}

1. [1] Lipsky Z, Romportl D. Classification and typology of cultural landscapes: methods and applications - the roleof landscape studies for sustainable development[M].Warsaw: University of Warsaw, 2007.

2. Vesna Koščak Miočić Stošić, Dora Tomić, Sonja Butula, et al. Landscape Vulnerability Assessment as a Method for the Strategic Environmental Assessment of Spatial Plans[J]. 2015, 23(1):76-79.

3. People's Publishing House. National Functional Area Planning [M]. Beijing: People's Publishing House, 2015(China).

4. Leng Hong. Construction and Application Prospect of Rural landscape Vulnerability Research Framework [J]. Southern Architecture 2018.5:3440(China).

5. Wang Yuncai. Research Progress and Prospect of Traditional Regional Cultural Landscape.[J] Journal of Tongji University (Social Science Edition). 2009(2) :18-24(China).

6. Xiong Can, Chen Weibin, Xu Bin. Expression of Regional culture in Rural Landscape Design -- A Case study of Fuyang Shuxi Village [J]. Architecture and Culture, 2017 (11) : 125-126(China).

7. Kuo Dai-zhi, Li Jian-Jian, Kang Wei-feng, Chen Dayong. Landscape Reconstruction and Ecological Restoration of Abandoned Quarry in Quanzhou city -- A Case study of Huangqishan Quarry Restoration Project [J]. Water Resources Science, Technology and Economy,2013 (1):37-39(China).

8. Zhu Jianning, Zheng Guangxia, Memories in The Quarry -- Reconstruction Design of Galaxy Park in Rizhao [J]. Chinese Gardens 2007 (1) : 18-24(China). 